\title{
Flame-made ceria nanoparticles
}

\author{
L. Mädler, W.J. Stark, and S.E. Pratsinis ${ }^{\text {a) }}$ \\ Institute of Process Engineering, ETH Zürich, CH-8092 Zürich, Switzerland
}

(Received 11 January 2002; accepted 12 March 2002)

Flame spray pyrolysis (FSP) has been used to synthesize high-surface-area ceria from cerium acetate in acetic acid solution. With the addition of an iso-octane/2-butanol mixture to that solution, homogeneous $\mathrm{CeO}_{2}$ nanoparticles were obtained. The specific surface area of the powders ranged from 240 to $101 \mathrm{~m}^{2} / \mathrm{g}$ by controlling the oxygen dispersion and liquid precursor flow rates through the flame. Furthermore, for production rates from 2 to $10 \mathrm{~g} / \mathrm{h}$ a constant average primary particle size could be obtained at selected process parameters. The ceria showed high crystallinity and primary particles with a stepped surface. The powder exhibited good thermal stability and conserved up to $40 \%$ of its initial specific surface area when calcinated for $2 \mathrm{~h}$ at $900{ }^{\circ} \mathrm{C}$. This shows the potential of FSP made ceria for high-temperature applications as in three-way catalysts or fuel cells.

\section{INTRODUCTION}

Ceria-based materials play a key role as an active component in the three-way catalyst for automotive exhaust gas treatment. Therefore, they have been extensively studied for their catalytic as well as special electronic and structural properties leading to a wealth of scientific contributions. ${ }^{1}$ One of the main goals is to lower the temperature required for oxygen diffusion through the material, which would lead to higher efficiency at lower temperatures. ${ }^{2}$ Therefore, ceria with enhanced textural and thermal properties and particularly with high specific surface area is sought.

Various wet-chemical preparation methods have been used for its synthesis such as precipitation, ${ }^{3,4}$ hydrothermal synthesis, ${ }^{5,6}$ microemulsions, ${ }^{7,8}$ and surfactantassisted precipitation ${ }^{9}$ to name just a few. In most of the studies, powders with specific surface areas less than $100 \mathrm{~m}^{2} / \mathrm{g}$ were made. The relative loss of surface area at temperatures as low as $1000 \mathrm{~K}$ is a general drawback of those methods. ${ }^{10}$ This decrease in total surface area can be reduced by doping with transition metals like zirconium. ${ }^{11}$ Recently mesoporous ceria of high specific surface area $\left(200 \mathrm{~m}^{2} / \mathrm{g}\right)$ with improved resistance to sintering $\left(40 \mathrm{~m}^{2} / \mathrm{g}\right.$ at $\left.1173 \mathrm{~K}\right)$ was made by a surfactantassisted precipitation. ${ }^{9}$ The improvement was mainly attributed to the structural arrangement and morphology.

Gas-phase (aerosol) technology provides an alternative route for the synthesis of high-surface-area ceria at high temperatures as it has been used to make a variety

\footnotetext{
a) Address all correspondence to this author. e-mail: pratsinis@ivuk.mavt.ethz.ch
}

of oxide nanoparticles. ${ }^{12}$ Spray pyrolysis of an aqueous solution of cerium nitrate at $400{ }^{\circ} \mathrm{C}$ resulted in hollow spheres with variable size and inhomogeneous surface with particle diameters between 100 and $2000 \mathrm{~nm} .{ }^{13}$ Suzuki et al. ${ }^{14}$ prepared polyhedra ceria particles of about $50 \mathrm{~nm}$ in diameter by atomizing a $1 \mathrm{M}$ cerium nitrate aqueous solution into fine droplets and reacting them in an argon (high-temperature radio frequency) inductively coupled plasma. Using the gas condensation technique, single-crystal ceria nanoparticles with a surface area up to $250 \mathrm{~m}^{2} / \mathrm{g}$ were synthesized for characterization purposes. ${ }^{15}$ With a similar process, Tschöpe and Ying ${ }^{16}$ utilized the inert-gas condensation method for synthesis of nanocrystalline La-doped $\mathrm{CeO}_{2-x}$ with a specific surface area of $80 \mathrm{~m}^{2} / \mathrm{g}$. A promising technique for the synthesis of ceria nanoparticles that has been used for synthesis of $\mathrm{Al}_{2} \mathrm{O}_{3}{ }^{17}$ and even mixed oxides ${ }^{18}$ is flame spray pyrolysis (FSP). The FSP has been used to make ceria with rather small specific surface area $\left(15 \mathrm{~m}^{2} / \mathrm{g}\right)$ while no information of the control of the process and product was given. ${ }^{18,19}$ However, FSP technology has proven to be able to produce various nanoparticle commodities with closely controlled characteristics and very high specific surface areas ${ }^{20}$ at production rates up to $180 \mathrm{~g} / \mathrm{min} .{ }^{21}$ Here the FSP is investigated for controlled synthesis of high specific surface area, crystalline $\mathrm{CeO}_{2}$ with high thermal stability.

\section{EXPERIMENTAL}

The experimental apparatus of FSP is described in detail by Mädler et al. ${ }^{20}$ According to this, the spray flame itself forms the reaction zone consisting of small evaporating and subsequently burning droplets which often leads to gas-phase synthesis of the desired product. 
Here, the liquid precursor feed was supplied by a syringe pump and atomized with oxygen (Pan Gas, purity $>99.95 \%$ ) resulting in a fine spray with a droplet mass median diameter in the range of 7 to $15 \mu \mathrm{m}$ as measured with Fraunhofer laser diffraction spectrometry (SympaTec) for a range of annular orifice gap areas of 180 to $480 \mu \mathrm{m}^{2} .{ }^{20}$ The flow rate of the oxygen dispersion gas was controlled by a mass flow controller (Bronkhorst) while a constant pressure drop (1.5 bar) at the nozzle tip was maintained through the orifice gap area. Evaporation and ignition of the spray was initiated by a smaller flame ring emerging from an annular gap of $0.15 \mathrm{~mm}$ width having a $6-\mathrm{mm}$ radius from the center of the nozzle. Premixed methane/oxygen gas flows through that ring at a total flow rate of $4.7 \mathrm{l} / \mathrm{min}\left(\mathrm{CH}_{4}\right.$, $1.5 \mathrm{l} / \mathrm{min} ; \mathrm{O}_{2}, 3.2 \mathrm{l} / \mathrm{min}$ ). An oxygen sheath flow (5 $\mathrm{l} /$ $\mathrm{min}$ ) surrounding the spray flame was supplied through a sintered metal plate ring of 8 -mm width and an inner radius of $9 \mathrm{~mm}$ from the center of the nozzle. The variable process parameters were the liquid feed rate (1-8 $\mathrm{ml} / \mathrm{min})$ and the oxygen dispersion gas flow rate $(1.5-81 / \mathrm{min})$. Powders made at specific parameter values were defined as the following: $x \mathrm{Ce} y$, where $x$ denotes the liquid feed rate in $\mathrm{ml} / \mathrm{min}$ and $y$ the oxygen flow rate in $1 / \mathrm{min}$. The maximum production rate reported was $10 \mathrm{~g} / \mathrm{h}$.

Cerium(III) acetate hydrate, $\mathrm{Ce}\left(\mathrm{CH}_{3} \mathrm{CO}_{2}\right)_{3} \cdot x \mathrm{H}_{2} \mathrm{O}$ $\left[\mathrm{Ce}(\mathrm{ac})_{3}\right.$, Aldrich, $\left.>99.9 \%\right]$, was used as precursor and was dissolved in glacial acetic acid (Fluka, >99.5\%) at $80{ }^{\circ} \mathrm{C}$ to obtain a $0.3 \mathrm{M} \mathrm{Ce}^{3+}$ solution. The solution was diluted either with acetic acid or a mixture of $80 \mathrm{vol} \%$ iso-octane (Fluka, >99.8\%) and 20 vol\% 2-butanol (Fluka, $>99.0 \%$ ) to obtain a $0.15 \mathrm{M} \mathrm{Ce}^{3+}$ solution. These precursor solutions were stable above $65^{\circ} \mathrm{C}$ and were filtered through a membrane filter (Titan, $0.2 \mu \mathrm{m}$ ) before filling into the syringe.

The particles were collected on a glass fiber filter (Whatmann GF/A, $15 \mathrm{~cm}$ in diameter) with the aid of a vacuum pump (Vaccubrand). The powder specific surface area, $A_{\mathrm{s}}$, was measured by nitrogen adsorption at $77 \mathrm{~K}$ and Brunauer-Emmett-Teller (BET) theory (Micromeritics Gemini 2375, with a 5-point isotherm $0.05 \leqslant p / p_{0} \leqslant 0.25$ ) after degassing the powder at least for $1 \mathrm{~h}$ at $150{ }^{\circ} \mathrm{C}$ in nitrogen. The reproducibility of the specific surface area was within $5 \%$. The average BETequivalent particle diameter, $d_{\mathrm{BET}}$, was calculated using $d_{\mathrm{BET}}=6 /\left(A_{\mathrm{s}} \cdot \rho_{\mathrm{p}}\right)$ assuming monodisperse particles, where the density of cubic ceria, $\rho_{\mathrm{p}}$, is $7.2 \mathrm{~g} / \mathrm{cm}^{3}{ }^{32}$ The results were cross-checked by recording a full adsorption isotherm (Micrometrics ASAP 2010 Multigas system, Norcross, GA). To study the thermal stability of the specific surface area, the as-prepared samples were placed for $2 \mathrm{~h}$ at the indicated temperature in a furnace under air applying a heating and cooling rate of $5 \mathrm{~K} / \mathrm{min}$. For every experimental point, a fresh sample was taken.
The product powder was analyzed also by transmission electron microscopy, (TEM) (Hitachi H600, operated at $100 \mathrm{kV}$ ) and high resolution transmission electron microscopy (HR-TEM) (Philips, CM30ST, $300 \mathrm{kV}$ ). The powder X-ray diffraction (XRD) spectra were recorded with a Bruker D8 advance diffractometer from $20^{\circ}$ to $70^{\circ}$, step $0.02^{\circ}$, and scan speed $0.24^{\circ} / \mathrm{min}$. Crystallite characteristics and average crystal size, $d_{\mathrm{XRD}}$, were obtained from the XRD spectra using the Topas 2.0 software (Bruker AXS, 2000) on the basis of the fundamental parameter approach (Rietveld method). ${ }^{23,24}$ The analysis was carried out by fitting the measured XRD pattern with the crystalline data of cubic ceria assuming that the background was a linear function (PDF $\left.81-792 .{ }^{22}\right)$. No indication for microstain in the particles was found and therefore omitted in the present analysis.

\section{RESULTS AND DISCUSSION}

\section{A. Precursor solution composition and process conditions}

Flame spray pyrolysis of $\mathrm{Ce}(\mathrm{ac})_{3}$ dissolved in pure acetic acid resulted in ceria powders (1Ce3) containing nanoparticles smaller than $10 \mathrm{~nm}$ and larger particles of several hundred nanometer in diameter (Fig. 1). The diffraction pattern of this highly crystalline powder revealed a bimodal crystal size distribution. This could be deconvoluted into crystals with an average size $d_{\mathrm{XRD}}=$ $155 \mathrm{~nm}$ corresponding to about one-third of the mass and the remaining two-thirds to crystals with $d_{\mathrm{XRD}}=8.1 \mathrm{~nm}$

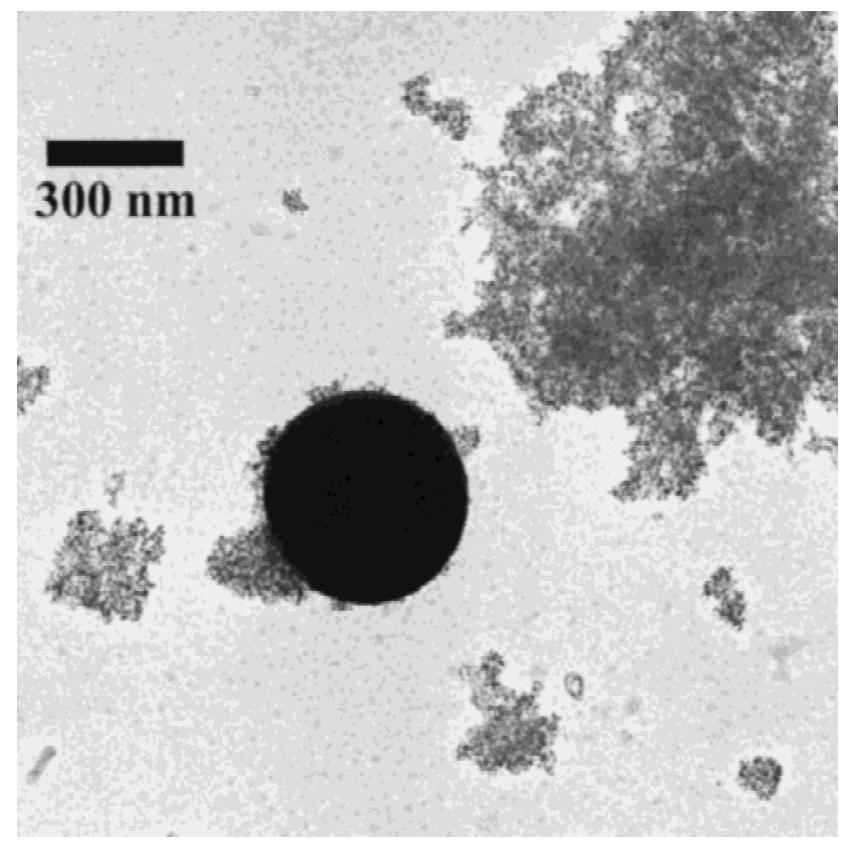

FIG. 1. TEM micrograph of FSP-made ceria prepared from $\mathrm{Ce}(\mathrm{ac})_{3}$ in pure acetic acid. The powder consists of both large and very small particles. 
(Fig. 2). The sum of both modes matches the measurement well (Fig. 2). Solutions of $\mathrm{Ce}(\mathrm{ac})_{3}$ in $50 \mathrm{vol} \%$ acetic acid, $40 \mathrm{vol} \%$ iso-octane, and $10 \mathrm{vol} \%$ 2-butanol instead of pure acetic acid resulted in a much more homogeneous powder (2Ce5) with $d_{\mathrm{XRD}}=5.9 \mathrm{~nm}$ while only $5 \%$ were attributed to larger crystals in the XRD spectra (Fig. 3). Note the excellent reconstruction of the XRD spectrum. Furthermore, increasing the liquid flow rate and decreasing the oxygen flow rate to prolong or stretch the spray flames resulted in a homogeneous powder $(8 \mathrm{Ce} 3)$ of high crystallinity that can be best reconstructed by a single cubic ceria crystal spectrum (Fig. 4).

Figure 5 shows the visually measured flame height as a function of the equivalence ratio $(\Phi+1)$ :

$$
\Phi=\frac{\left(\frac{\dot{n}_{\text {oxidant }}}{\dot{n}_{\text {fuel }}}\right)_{\text {stoich. }}}{\left(\frac{\dot{n}_{\text {oxidant }}}{\dot{n}_{\text {fuel }}}\right)_{\text {real }}},
$$

where "oxidant" is the oxygen gas for dispersion molar flux and "fuel" is the precursor solution molar flux. The stoichiometric ratio of $\dot{n}_{\text {oxidant }}$ and $\dot{n}_{\text {fuel }}$ defines the mole quantity of oxidant needed to completely burn $1 \mathrm{~mol}$ of fuel, while the real ratio defines the molar flux of oxidant and fuel in the system. In this figure, data points represent the flame height at different oxygen dispersion gas

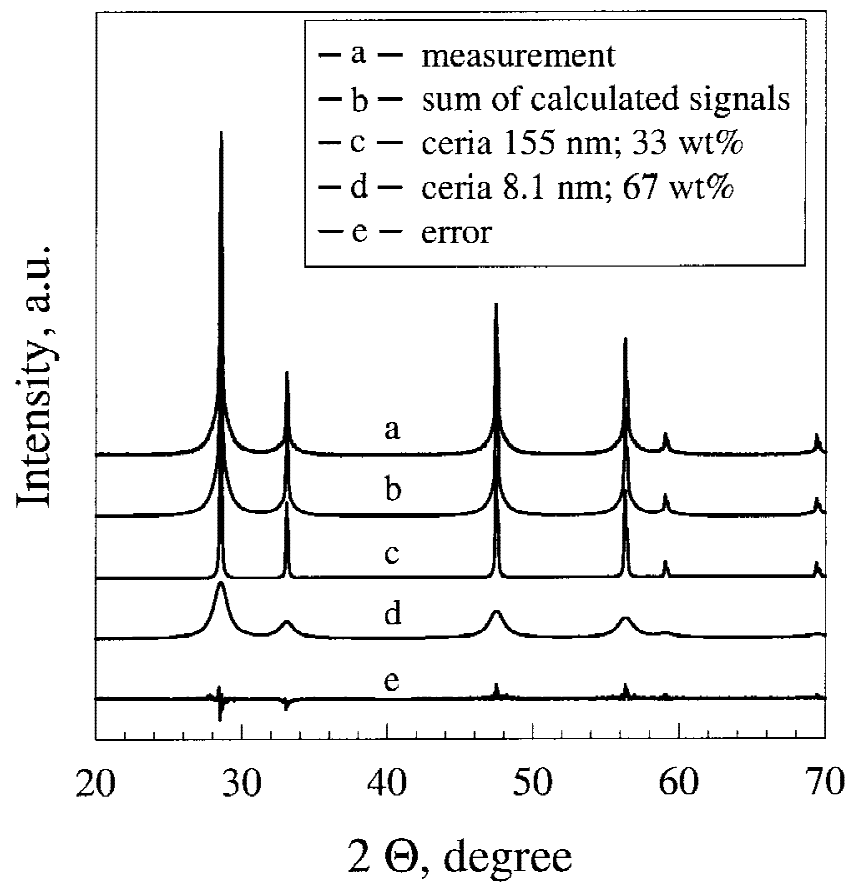

FIG. 2. XRD pattern of FSP-made ceria (1Ce3) with strong bimodal crystal size prepared from $\mathrm{Ce}(\mathrm{ac})_{3}$ in pure acetic acid. One-third of the powder mass consists of large crystals (average size $155 \mathrm{~nm})(\mathrm{GOF}=$ 1.38). The measured XRD was fitted with two cubic ceria modes (PDF 81-792).

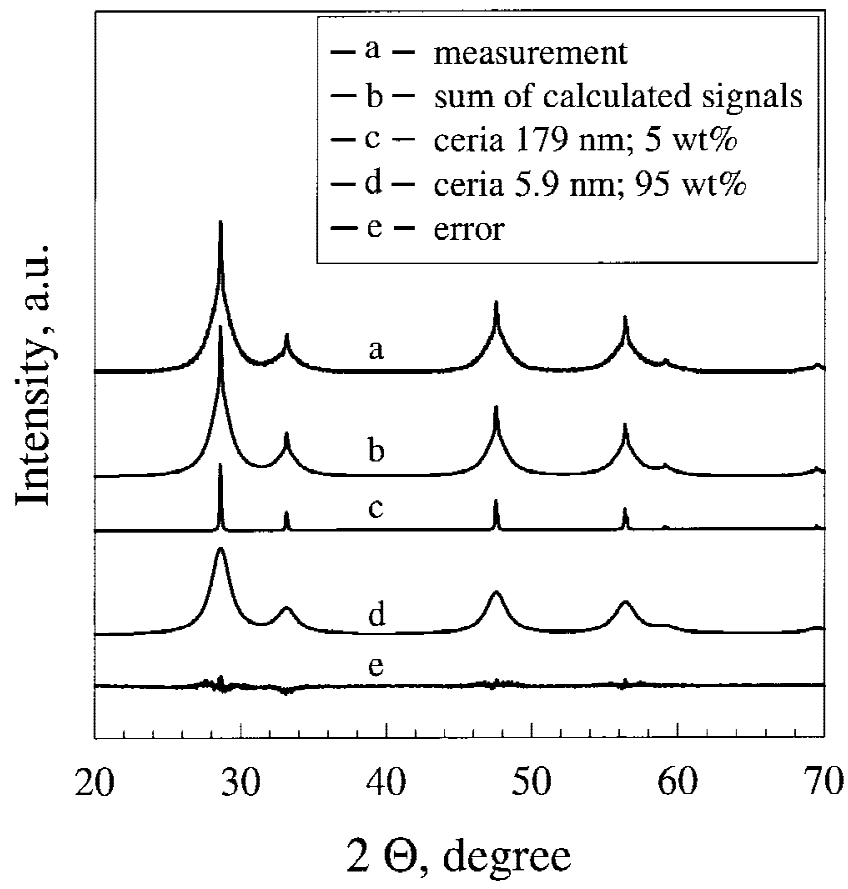

FIG. 3. XRD pattern of FSP-made ceria (2Ce5) prepared from 50 vol\% acetic acid, $40 \mathrm{vol} \%$ iso-octane, and $10 \mathrm{vol} \%$ 2-butanol showing a bimodal crystal size distribution. The larger crystals (average size $179 \mathrm{~nm})$ contribute about $5 \%$ of the total mass $(\mathrm{GOF}=1.38)$.

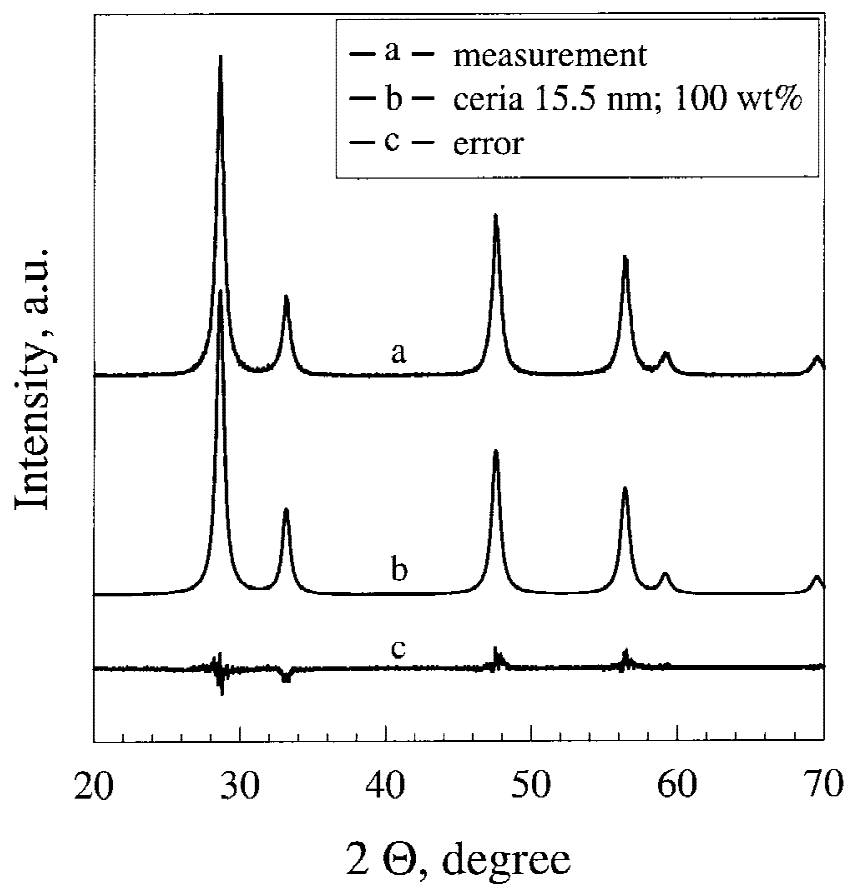

FIG. 4. XRD pattern of FSP-made ceria (8Ce3) with homogeneous crystal size prepared from $50 \mathrm{vol} \%$ acetic acid, $40 \mathrm{vol} \%$ iso-octane, and 10 vol\% 2-butanol at high liquid feed rate. No large crystals can be found, and the spectrum corresponds nicely to a single average crystal size of $15.5 \mathrm{~nm}(\mathrm{GOF}=1.40)$. 


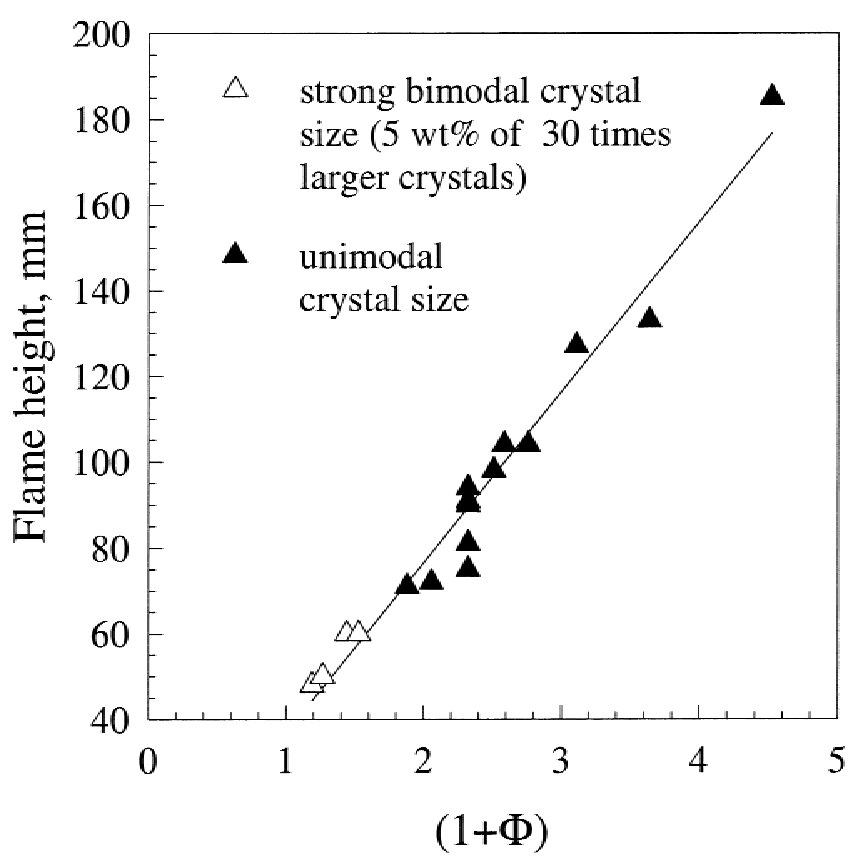

FIG. 5. Visually measured flame height as function of equivalence ration $\Phi$ [Eq. (1)] for different flame conditions at various feed and oxygen flow rates.

flow rates and at various liquid feed rates, respectively. The points fall nearly on a straight line as it is common for shear-induced spray flames. ${ }^{20,25}$ The open symbols in Fig. 5 represent the powders with bimodal crystal size distribution made at $\Phi<1$ (flame heights less than $60 \mathrm{~mm}$ ). The mass fraction of larger particles is less than $7 \%$ for all powders made using the acetic acid/ iso-octane/2-butanol mixture containing $\mathrm{Ce}(\mathrm{ac})_{3}$. For longer flames $(\Phi>1)$, the powder is homogeneous as shown by the XRD spectra, and no large crystals or particles were detected by TEM/scanning electron microscopy (SEM).

The appearance of large crystals $\left(d_{\mathrm{p}}>100 \mathrm{~nm}\right)$ in the TEM and XRD analysis may indicate that two particle formation mechanisms are present independently. Large particles may be formed directly from precursor droplets that do not completely evaporate. Particles with sizes below $10 \mathrm{~nm}$ could be formed by precursor evaporation and subsequent gas-phase reaction, ceria nucleation, surface growth, coagulation, and sintering. The addition of iso-octane that has high combustion enthalpy and high evaporation/burning rate ${ }^{20,26}$ increases the flame temperature enhancing precursor evaporation that therefore reduces the formation of residue. Similar homogeneous ceria powders were obtained for longer flames (larger equivalence ratios) where the particles experience high temperatures and long residence times. This was shown by nonintrusive Fourier transform infrared (FTIR) temperature measurements in a silica producing spray flame. ${ }^{20}$
The product particle size can be controlled by the liquid feed and oxygen dispersion flow rates. With these parameters the specific surface area was varied from $240 \mathrm{~m}^{2} / \mathrm{g}(1 \mathrm{Ce} 1.5)$ to $101 \mathrm{~m}^{2} / \mathrm{g}(8 \mathrm{Ce} 3)$ within the operation window for synthesis of homogeneous powders. Figure 6 shows the average particle size as a function of the precursor feed rate at constant oxygen dispersion gas flow, $5 \mathrm{l} / \mathrm{min}(x \mathrm{Ce} 5)$. The BET-equivalent average particle diameter, $d_{\mathrm{BET}}$, and the average crystal size, $d_{\mathrm{XRD}}$ (small crystal fraction for bimodal powder, open symbols), increase from 3 to $5.5 \mathrm{~nm}$ and from 4.5 to $10.5 \mathrm{~nm}$, respectively. Increasing the precursor feed rate increases the total concentration of ceria and fuel within the spray flame resulting in longer flames that lead to longer particle residence times at high temperatures. Both effects contribute to the production of larger particles by increased coagulation and sintering rates as it has been shown in synthesis of titania in vapor flame reactors. ${ }^{27}$ With increase of the oxygen flow rate, the opposite effects are encountered: reduction of ceria concentration by dilution and reduction of flame height by acceleration of combustion by the abundance of oxygen or enhanced mixing that is accompanied by higher cooling rates leading to smaller particle sizes. This is consistent with the effect of oxidant flow rate in synthesis of silica in turbulent diffusion flame reactors. ${ }^{28,29}$

Figure 7 shows the effect of oxygen flow rate on product average particle size at constant precursor feed rate of $8 \mathrm{ml} / \mathrm{min}$ (8Cey). The oxygen flow rate was varied from

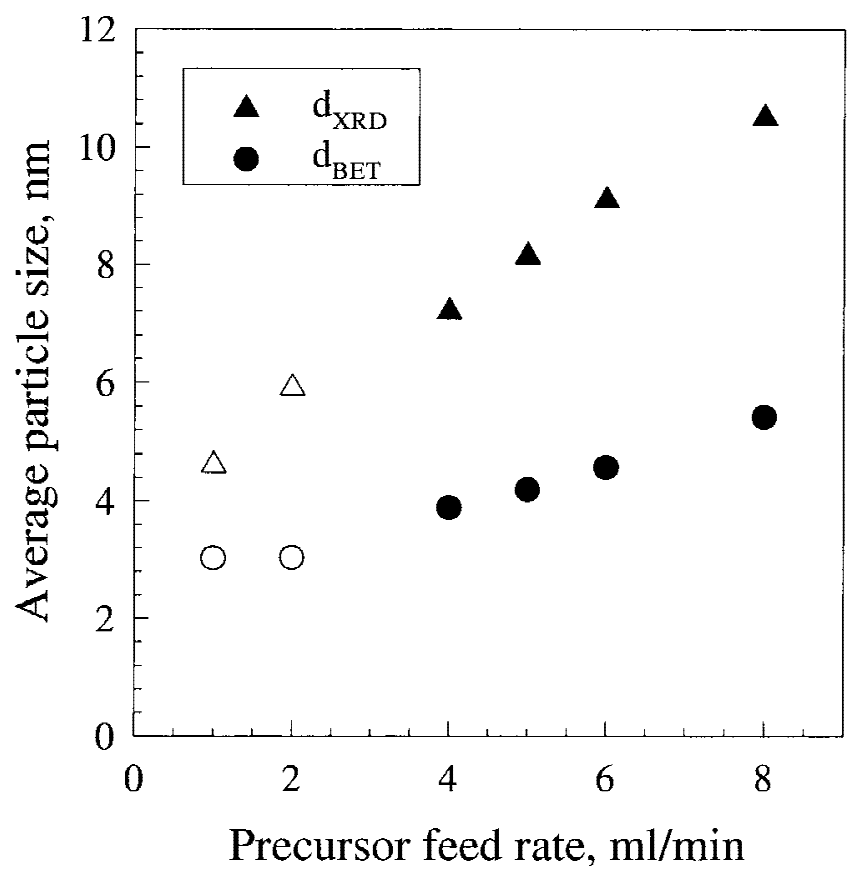

FIG. 6. BET-equivalent average particle size, $d_{\mathrm{BET}}$, and average crystal size, $d_{\mathrm{XRD}}$, for powders produced at different feed rates at an oxygen flow rate of $51 / \mathrm{min}(x \mathrm{Ce} 5)$. Open symbols represent powders with strong bimodal crystal size, and the $d_{\mathrm{XRD}}$ is that of the fine mode. 
3 to $81 /$ min leading to the decrease of $d_{\mathrm{BET}}$ and $d_{\mathrm{XRD}}$ from 7 to $4.5 \mathrm{~nm}$ and from 15 to $9 \mathrm{~nm}$, respectively. It can be inferred that precursor feed rate and oxygen dispersion gas flow rate may balance and compensate each other for attainment of a specific particle size. Figure 8 shows how the product particle size can be kept constant at increasing production rates $(x \mathrm{Cey}, x=y)$. The average particle sizes were kept at $d_{\mathrm{BET}}=4 \mathrm{~nm}$ or $d_{\mathrm{XRD}}=$ $8 \mathrm{~nm}$, while the production rate was varied from 2 to $10 \mathrm{~g} / \mathrm{h}$. This is an important feature for scaling-up of this process.

In all ceria powders the BET-equivalent average diameter, $d_{\mathrm{BET}}$, and the average crystal size obtained from the fundamental parameter approach, $d_{\mathrm{XRD}}$, differ by a factor of about 0.5. Possible reasons for this difference is polydispersity since $d_{\mathrm{BET}}$ is a surface-weighted particle property while $d_{\mathrm{XRD}}$ is a mass-weighted particle property which would lead to $d_{\mathrm{BET}} / d_{\mathrm{XRD}}<1$. Figure 9 shows a HR-TEM image of one homogeneous nanocrystalline powder $(8 \mathrm{Ce} 3)$ where a broad spectrum of crystal/ particle sizes can be seen. The picture also shows a stepped surface which is a result of the high crystallinity. This surface topology can also lead to larger surface area and therefore to $d_{\mathrm{BET}} / d_{\mathrm{XRD}}<1$. A full nitrogen adsorption isotherm at $77.4 \mathrm{~K}$ (8Ce3 powder) showed a type IV isotherm, typical of a mesoporous samples with a low micropore content. ${ }^{28}$ However, the pore size distribution calculated from the desorption branch revealed a bimodal pore size distribution. About $90 \%$ of the pore volume corresponds to pores larger than $10 \mathrm{~nm}$ (intraparticles

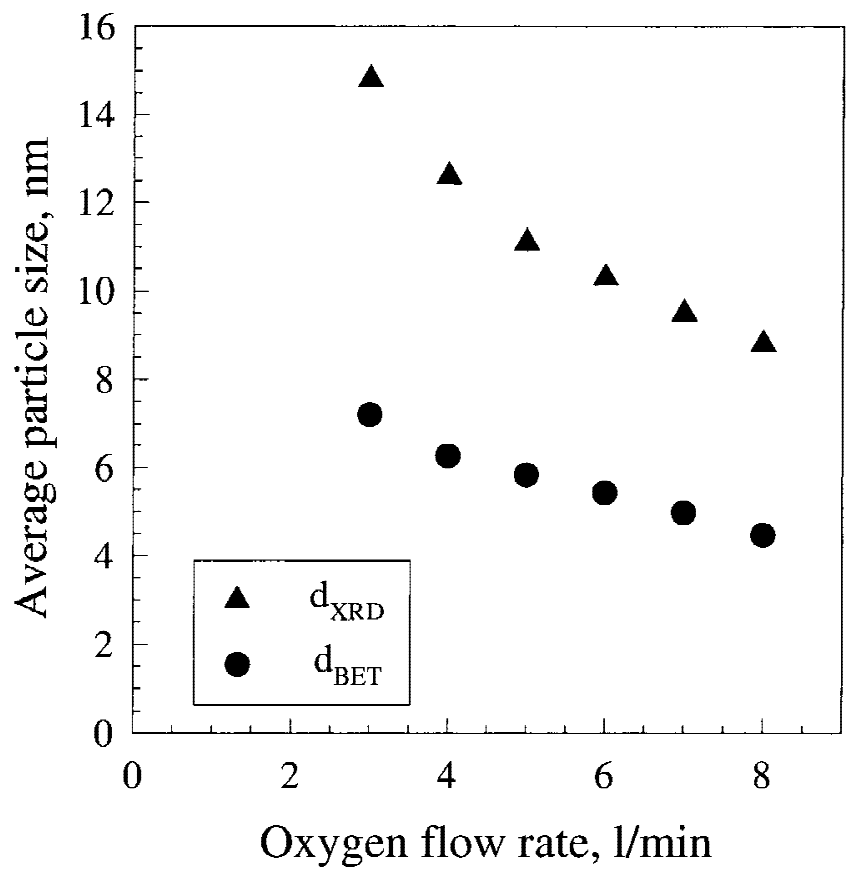

FIG. 7. BET-equivalent average particle size, $d_{\mathrm{BET}}$, and average crystal size, $d_{\mathrm{XRD}}$, for powders produced at different oxygen flow rates and at a liquid feed rate of $8 \mathrm{ml} / \mathrm{min}(8 \mathrm{Cey})$. pores between aggregates) with an average diameter of about $30 \mathrm{~nm}$ and $10 \%$ to pores smaller than $10 \mathrm{~nm}$ with an average diameter of about $1.5 \mathrm{~nm}$ (intraparticles pores between primary particles and at crystalline surface steps) (Fig. 10). The corresponding $t$-plot showed a positive intercept and revealed that about $90 \%$ of the total

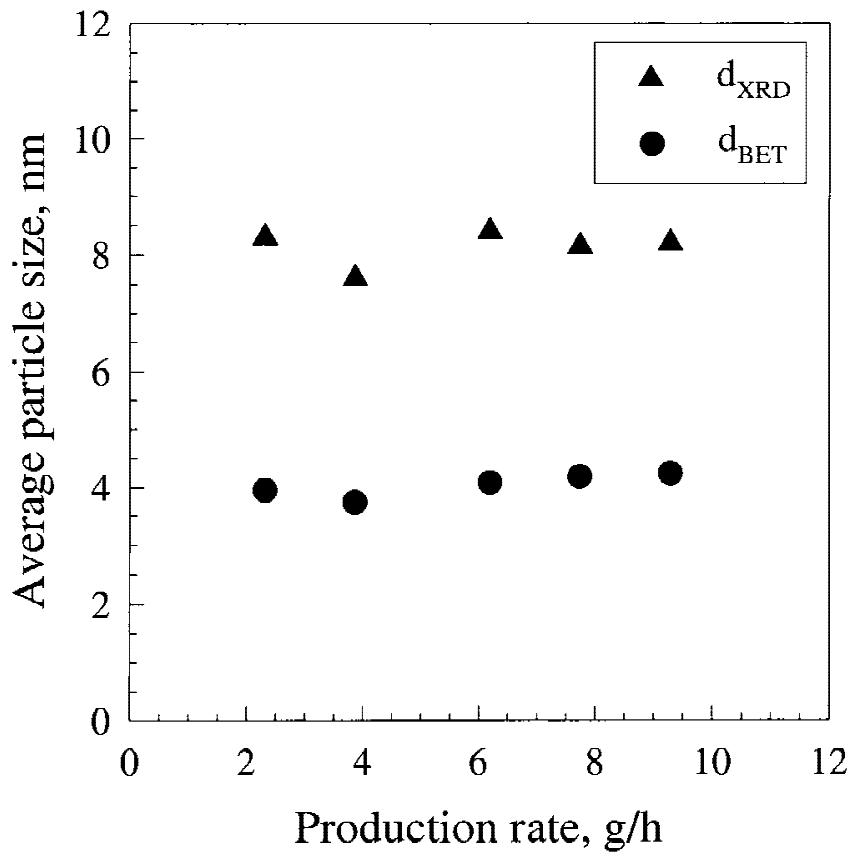

FIG. 8. BET-equivalent average particle size, $d_{\mathrm{BET}}$, and average crystal size, $d_{\mathrm{XRD}}$, for powders produced at different powder production rates while keeping the liquid feed to oxygen dispersion gas ratio constant $(x \mathrm{Cey}, x=y)$.

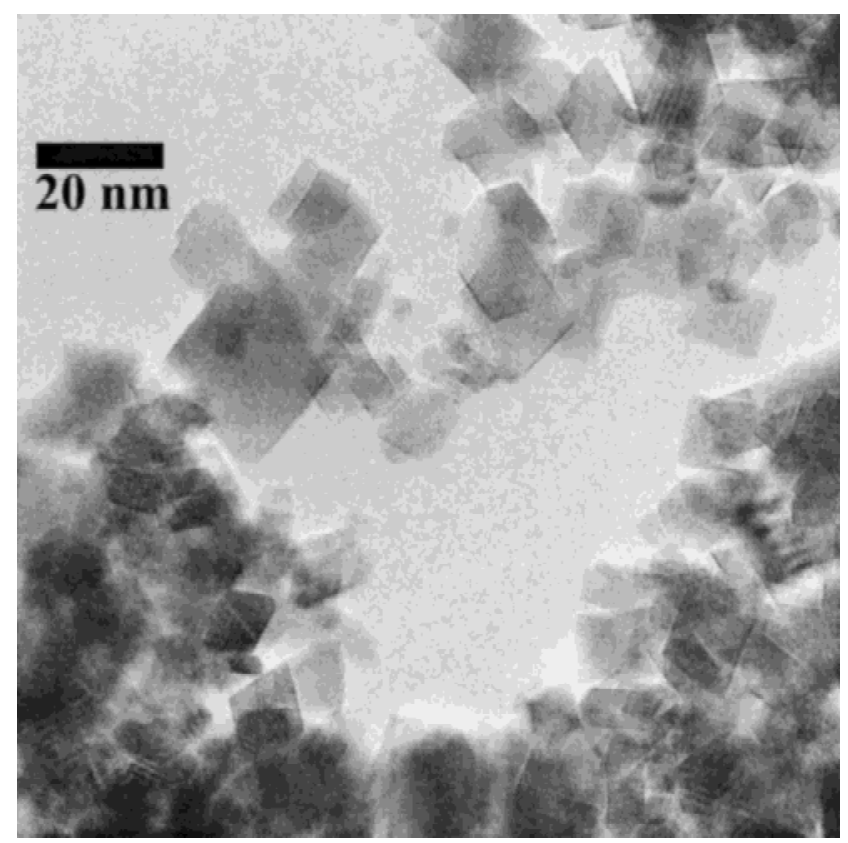

FIG. 9. HR-TEM micrograph of as-prepared FSP-made ceria (8Ce3). The powder shows high crystallinity and a stepped crystals surface. 
surface corresponds to external surface area. The agreement to the BET-derived specific surface area was within $2 \%$. The microporous fraction of the surface area (10\%) may also lead to a slight overestimation of $d_{\mathrm{BET}}$ and therefore to $d_{\mathrm{BET}} / d_{\mathrm{XRD}}<1$. Important to note is the fact that $90 \%$ of the surface area is attributed to external surface area (large pores) which is easily accessible.

\section{B. Thermal stability of FSP-made $\mathrm{CeO}_{2}$}

The evolution of the $\mathrm{CeO}_{2}$ specific surface area as a function of calcination temperature for two selected homogeneous powders $\left(5 \mathrm{Ce} 5, A_{\mathrm{s}}=177 \mathrm{~m}^{2} / \mathrm{g} ; 8 \mathrm{Ce} 3, A_{\mathrm{s}}=\right.$ $101 \mathrm{~m}^{2} / \mathrm{g}$ ) are shown in Fig. 11 along with those of a commercial powder (Rhône-Poulenc, Perrichon et al. ${ }^{10}$ and a representative sample from the literature. ${ }^{9}$ A nearly linear decrease of the $A_{\mathrm{s}}$ was obtained for the FSP-made powders. The powder with lower initial $A_{\mathrm{s}}(8 \mathrm{Ce} 3)$ was more stable than the $5 \mathrm{Ce} 5$ powder. However, both FSPmade powders showed an excellent thermal stability when compared to commercial ceria which showed a pronounced loss in specific surface area for temperatures above $970 \mathrm{~K}$. There, the mesoporous structure collapsed and the surface area decreased drastically. Perrichon et al. ${ }^{10}$ claimed that carbonate species stabilize the structure that collapses when they are eliminated at around 870 to $970 \mathrm{~K}$. At this temperature, the FSP-made ceria powder preserved more than $60 \%(5 \mathrm{Ce} 5)$ or $80 \%(8 \mathrm{Ce} 3)$ of its initial surface area.

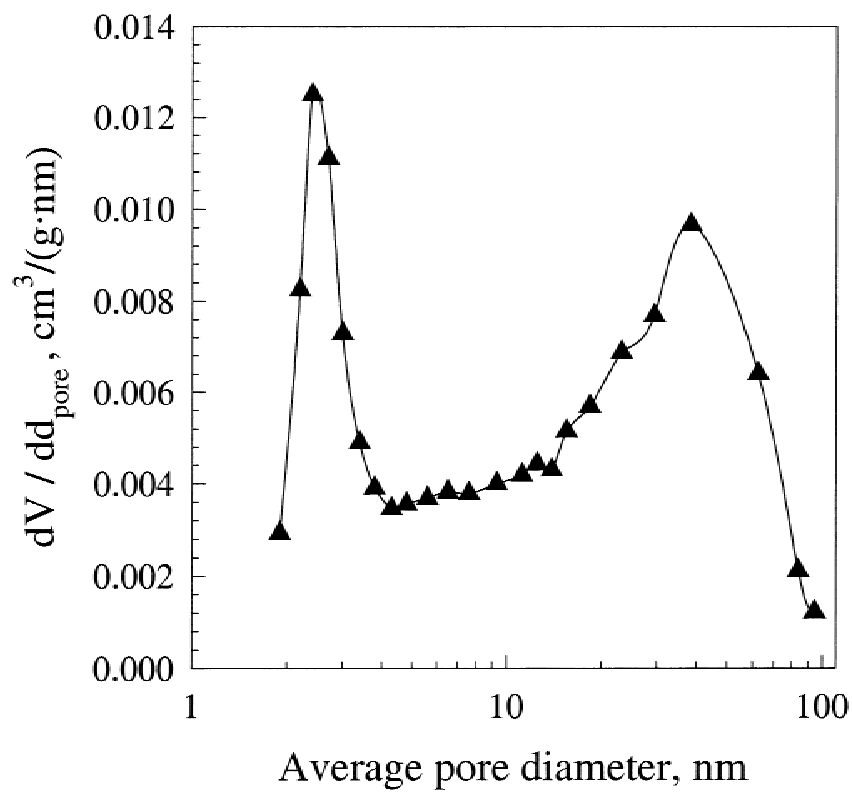

FIG. 10. Pore size distribution for a FSP-made ceria sample (8Ce3). About $90 \%$ of the pore volume corresponds to pores larger than $10 \mathrm{~nm}$ (intraparticle pores between aggregates) and $10 \%$ to pores smaller than $10 \mathrm{~nm}$ (intraparticle pores between primary particles and at crystalline surface steps)
Figure 11 shows a comparison with one of the best ceria in the literature prepared by a surfactant-assisted precipitation. ${ }^{9}$ The specific surface area (SSA) of precipitated ceria was $40 \mathrm{~m}^{2} / \mathrm{g}$ after $2 \mathrm{~h}$ at $1173 \mathrm{~K}$, which is essentially the same as that of the FSP-made ceria (8Ce3)

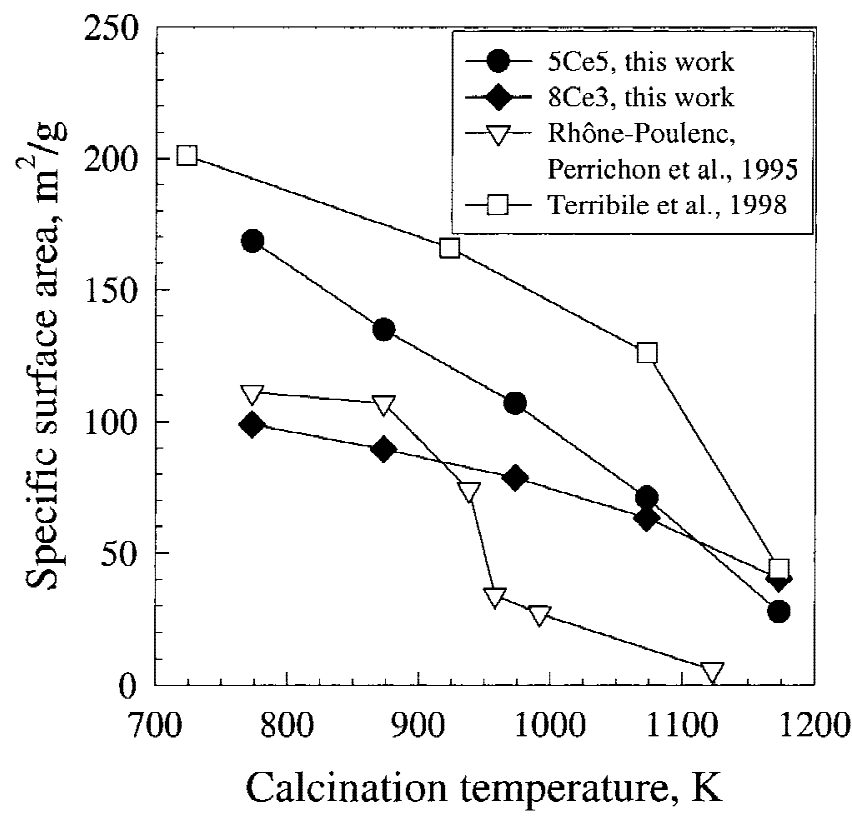

FIG. 11. Ceria specific surface area after $2 \mathrm{~h}$ calcination at a given temperature in air. Filled symbols refer to this work using FSP-made ceria with an initial surface area of $177 \mathrm{~m}^{2} / \mathrm{g}$ (5Ce5) and $101 \mathrm{~m}^{2} / \mathrm{g}$ (8Ce3). They are compared with commercial ceria (Rhône-Poulenc ${ }^{10}$ ) and high specific surface area ceria prepared with a surfactant-assisted precipitation method. ${ }^{9}$

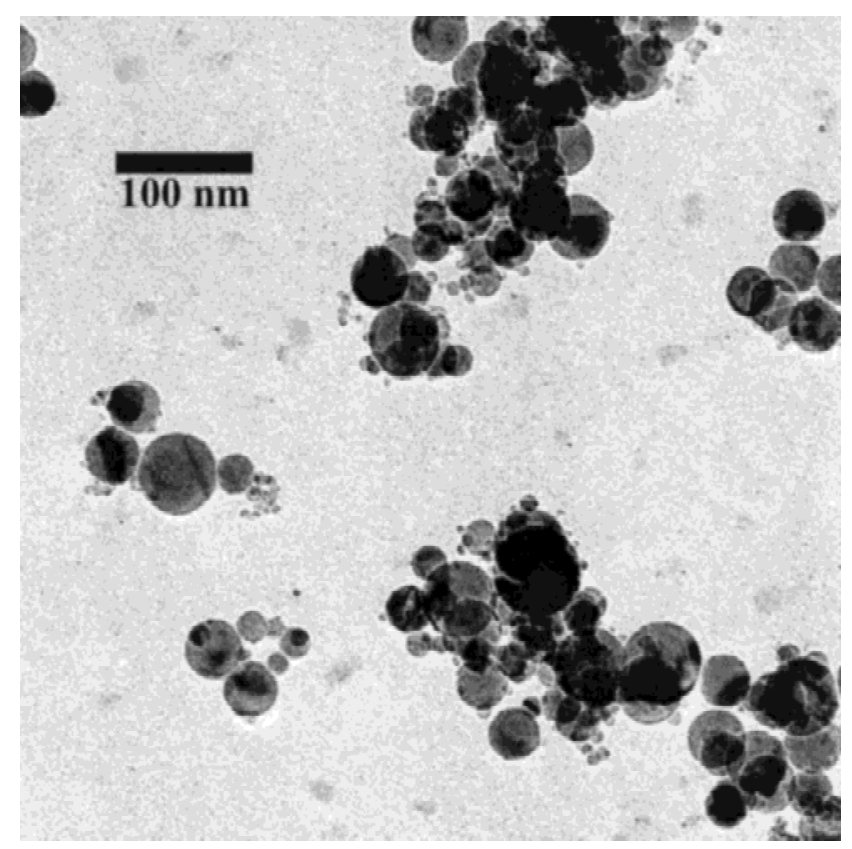

FIG. 12. TEM micrograph of ceria powder (8Ce3) after calcination at $1173 \mathrm{~K}$ for $2 \mathrm{~h}$ in air. 
processed at equivalent conditions. The structural advantage of the highly crystalline FSP-made ceria powder may arise from the fact that it consisted of distinct primary particles. This structure is conserved even up to $1173 \mathrm{~K}$ as observed by TEM (Fig. 12). The linear decrease with calcination temperature of the $8 \mathrm{Ce} 3$ powder SSA indicates its structural stability since no collapse occurred and still up to $40 \%$ for the $8 \mathrm{Ce} 3$ powder of its initial SSA were conserved at $1173 \mathrm{~K}$. These results highlight the potential of FSP-made ceria for catalyst support or promoter at high temperatures.

\section{SUMMARY}

Synthesis of ceria with specific surface areas up to $240 \mathrm{~m}^{2} / \mathrm{g}$ was demonstrated by FSP of an acetate precursor dissolved in acetic acid. Addition of iso-octane/2butanol in solution accelerated precursor evaporation and gas-phase reaction that resulted in homogeneous powders as shown by electron microscopy and XRD. The powders showed high crystallinity and consisted of primary particles with an external specific surface area over $90 \%$. The specific surface area and crystal size were controlled by the FSP liquid feed rate and oxygen dispersion gas flow rate. A set specific surface area was achieved during a fivefold increase of production rate by balancing the liquid feed and oxygen flow rates.

The FSP-made ceria showed good thermal stability when calcinated for $2 \mathrm{~h}$ in air for temperatures up to $1173 \mathrm{~K}$. Compared to conventionally prepared ceria no collapse of the surface area was observed during heating. This can be attributed to the high crystallinity and homogeneous morphology of the FSP-made powder. The powder showed a linear loss of the specific surface area with calcination temperature. Up to $40 \%$ of the initial SSA was conserved after calcination at $1173 \mathrm{~K}$, resulting in about $40 \mathrm{~m}^{2} / \mathrm{g}$ in the final product.

\section{ACKNOWLEDGMENTS}

The research was supported by the Kommission für Technologie und Innovation (KTI) TOP NANO 21, Grant No. 5351.1, Switzerland, and TH Gesuch 19/01-1.

We gratefully acknowledge the technical support of Dr. M. Müller and Dr. F. Krumeich providing the EM and HR-TEM facilities.

\section{REFERENCES}

1. A. Trovarelli, Catal. Rev. Sci. Eng. 38, 439 (1996).

2. A. Trovarelli, F. Zamar, J. Llorca, C. deLeitenburg, G. Dolcetti, and J.T. Kiss, J. Catal. 169, 490 (1997).

3. B. Djuricic and S. Pickering, J. Eur. Ceram. Soc. 19, 1925 (1999).

4. L.A. Bruce, M. Hoang, A.E. Hughes, and T.W. Turney, Appl. Catal., A 134, 351 (1996).

5. M. Hirano and M. Inagaki, J. Mater. Chem. 10, 473 (2000).

6. Y. Hakuta, S. Onai, H. Terayama, T. Adschiri, and K. Arai, J. Mater. Sci. Lett. 17, 1211 (1998).

7. A. Martinez-Arias, M. Fernandez-Garcia, V. Ballesteros, L.N. Salamanca, J.C. Conesa, C. Otero, and J. Soria, Langmuir 15, 4796 (1999).

8. T. Masui, K. Fujiwara, Y.M. Peng, T. Sakata, K. Machida, H. Mori, and G. Adachi, J. Alloy. Compd. 269, 116 (1998).

9. D. Terribile, A. Trovarelli, J. Llorca, C. deLeitenburg, and G. Dolcetti, J. Catal. 178, 299 (1998).

10. V. Perrichon, A. Laachir, S. Abouarnadasse, O. Touret, and G. Blanchard, Appl. Catal., A 129, 69 (1995).

11. J. Kaspar, P. Fornasiero, and M. Graziani, Catal. Today 50, 285 (1999).

12. S.E. Pratsinis, Prog. Energy Combust. 24, 197 (1998).

13. M. ValletRegi, F. Conde, S. Nicolopoulos, C.F. Ragel, and J.M. Gonzalez-Calbet, in Synthesis and Properties of Mechanically Alloyed and Nanocrystalline Materials, Pts 1 and 2Ismanam-96, Materials Science Forum (Transtec Publications Ltd, Zurich-Uetikon, Switzerland, 1997), Vol. 235-279, pp. 291-296.

14. M. Suzuki, M. Kagawa, Y. Syono, and T. Hirai, J. Mater. Sci. 27, 679 (1992).

15. N. Guillou, L.C. Nistor, H. Fuess, and H. Hahn, Nanostruct. Mater. 8, 545 (1997).

16. A. Tschöpe and J.Y. Ying, Nanostruct. Mater. 4, 617 (1994).

17. M. Sokolowski, A. Sokolowska, A. Michalski, and B. Gokieli, J. Aerosol Sci. 8, 219 (1977).

18. R.M. Laine, R. Baranwal, T. Hinklin, D. Treadwell, A. Sutorik, C. Bickmore, K. Waldner, and S.S. Neo, Key Eng. Mater. 159, 17 (1999).

19. R.M. Laine, T. Hinklin, G. Williams, and S.C. Rand, in Metastable, Mechanically Alloyed and Nanocrystalline Materials, Pts 1 and 2, of Materials Science Forum (Trans Tech Publications Ltd, Zurich-Uetikon, Switzerland, 2000), Vol. 343-3, pp. 500-510.

20. L. Mädler, H.K. Kammler, R. Mueller, and S.E. Pratsinis, J. Aerosol Sci. 33, 369 (2002).

21. A. Kilian and T.F. Morse, Aerosol Sci. Technol. 34, 227 (2001).

22. M. Wolcyrz and L. Kepinski, J. Solid State Chem. 99, 409 (1992).

23. R.W. Cheary and A. Coelho, J. Appl. Crystallogr. 25, 109 (1992).

24. R.W. Cheary and A.A. Coelho, J. Appl. Crystallogr. 31, 851 (1998).

25. A.N. Karpetis and A. Gomez, Combust. Flame 121, 1 (2000).

26. E. Gutheil, Modeling of Technical Spray Flames (VDI Verlag, Düsseldorf, Germany, 1998).

27. S.E. Pratsinis, W.H. Zhu, and S. Vemury, Powder Technol. 86, 87 (1996).

28. W.J. Stark, S.E. Pratsinis, and A. Baiker, J. Catal. 203, 516 (2001).

29. H. Briesen, A. Fuhrmann, and S.E. Pratsinis, Chem. Eng. Sci. 53, 4105 (1998). 